\title{
Estimating the impact of the Norwegian Introduction Programme on integration using a Regression Kink Design (RKD): Pre-registration
}

Authors: Meng Le Zhang with Henrik Lindegaard Andersen and Liv Osland

Acknowledgements: We would like to thank Gurleen Popli for her feedback on an earlier draft of this document.

Final version for OSF registration: 11 Nov 2021

Second version date (sent for feedback): 1 October 2021

First version date: 2 June 2021

Purpose of this document:

- Explain the research design

- Guide data collection; in this case ordering data from Stats Norway

- inform project feasibility, including power tests

- Outline hypotheses and statistical methods

The latter point is to prevent post-hoc hypotheses generation after seeing the results. We may still alter the research design and add additional questions (e.g. tests of treatment heterogeneity). However, post-hoc analyses are more exploratory and vulnerable to issues such as data mining.

\section{Introduction}

The Introduction Programme offers language, employment and cultural training for new migrants in Norway. Attendance on the programme is mandatory for most refugees and family reunification migrants (with non-Nordic spouses). Migrants are given a special benefit for attendance (calculated by hours). The amount changes based on an age cut-off: under $25 \mathrm{~s}$ earn benefits at $2 / 3$ the rate of those over 25. Benefits are calculated per hour of programme attendance.

The benefit age cut-off can be used to measure the effects of cash incentives on programme attendance and its knock-on effect on integration outcomes such as education and employment. We 
propose a Regression Kink Design (RKD) to answer our primary research questions:

1. What is the effect of the age-cut off (via benefit rate) on programme participation?

2. What is the effect of the age-cut off (via benefit rate) on integration outcomes inclusive of employment status, wages, and further education/ training?

3. What is the direct effect of programme participation on integration outcomes? This is estimated using the results of questions 1 and 2 .

4. What is the variance in programme attendance effects across municipalities? This is looking at the effects identified in RQs 1 and 2 across different intervention sites.

5. Do heterogeneous effects exists for a) programme participation and b) integration outcome? This will involve subgroup analysis.

In additon, we will answer a related question:

6. What are the effects of the changes in rights and obligations at age 55 on programme participation? Over 55s have the right but not the obligation to participate in the Introduction Programme.

RQ6 is a scoping question; if a change in participation occurs around this age then this means that the age 55 cut-off can used for further studies (conditional on sample size).

\section{Background}

The Introduction Programme is an integration programme aimed at addressing Norwegian language proficiency, vocational skills, and social studies. Introduced under the 2003 introduction act, it is mandatory and obligatory for migrants who are either (i) refugees and/or (ii) family reunion migrants (with non-Nordic spouses) between 18-55 with basic qualifications. It is expected that participant attend the course full-time. It offers up to 2 years of training which is tailored to the individual (up to 3 years under exceptional circumstances). The programme officially started in September 2004 (Hernes et al 2019).

The incentives for programme attendance are not means-tested but are instead dependent on hours of programme attendance. The annual benefit for full attendance is double basic national insurance ( $2 \mathrm{G} \approx 2 \times 98,000 \mathrm{NOK} \approx £ 16,000$ ). The rate is only $2 / 3$ for under $25 \mathrm{~s}$-- the increase in benefits upon reaching 25 is substantial ( $<£ 6,000$ annually in GBP). The benefit is calculated by hour although the schedule of payment (e.g. monthly, weekly) is up to municipalities. This means that as soon as a participant turns 25 , their next hours of participation are paid at the full benefit rate (2G). People nonetheless will drop out of the programme due to the opportunity cost of other activities (e.g. work). 
It is the duty of migrants after settlement into a municipality to request entry to the programme. The municipality then must offer a place to eligible participants within three months after application. The duty and responsibility to provide the programme exist for up to five years after eligible participants settle in the municipality (Introduction Act 2003). Municipalities deliver the programme, so there is variance in the intervention and each municipality has the right to test language proficiency beforehand to assess eligibility. The funds come from the central government, and municipalities are rewarded if a person completes the programme (according to the 2003 Act).

Participants exit the programme once they have accepted an offer of work or education; used up their available time (one year extension is possible under the 2003 Act) or -- in rare instance -- been kicked out of the programme due to poor attendance / other reasons (Kvali et al 2007). Most participants leave the programme in these ways (p.12, ibid). Technially participants may simply leave without getting work or education; we know of no other punitive actions other than the denial of Introduction benefits. Participants can interrupt the programme due to illness, leave, or relocation.

The reasons for lower benefits payments for under 25s, as given by the Norwegian Government (2002, section 13.7), are:

- primarily to avoid disincentivising young people from continuing on the Introduction Programme instead of (ordinary) education;

- younger people have lower expenses

Age 25 is given as the cut-off because the Legalisation committee says that most young people would finish further education by age 25 (presumably based on statistics for native Norwegians). The Government decided to make age 25 the only consideration in calculating benefit rates to simplify and strengthen the incentive structure. As far as we can tell, the choice of 25 as the cut-off age -- instead of 23, 24 or 26 -- is entirely arbitrary. The Government consultation could find no other national benefits that age-differentiates around that age (although see limitations).

\section{Research design: Regression Kink Design using age}

In summary, as far as we know, the total benefits received is deterministically dependent on age and hours of programme attendance. Programme participation benefits increase substantially starting at age 25 and the programme is expected to last up to 2 years. Therefore, those who are closer to reaching 25 at the start of the programme can expect to earn more benefits throughout the lifetime of the programme. We conjecture that this will lead to higher programme participation for older 
individuals all else being equal. This is primarily due to (i) the promise of increased incentives and (ii) the knock-on effect of higher household income.

An example of the former; a 24-year-old might spend more time on the programme compared to a 23year-old due to the prospects of increased incentives later on. Those who begin at 25 will expect to collect the same level of benefits for participation as they get older.

An example of the later; a large proportion of participants are on other benefits and face financial challenges that can impede on their development on their programme and their choices outside it (Kvali et al 2007). Faced with challenges, younger participants may exit the programme earlier by accepting low paid work that nonetheless pay better than the Introduction Programme benefits. Older participant who spend more time on higher benefit rates may benefit from the extra household income and the reduced financial stress may lead to higher participation/ lower absenteeism/ lower incidences of leave for whatever reason.

We can test for this expected change in the relationship between age and programme participation in age ranges before 25 . This change can be captured by a change in a regression line (i.e. a kink). RKD has a similar logic to Regression Discontinuity Designs (RDD). Excellent introductions to the subject can be found in McKenzie (2016) and Card et al (2017). The figure below shows the difference between the two designs:

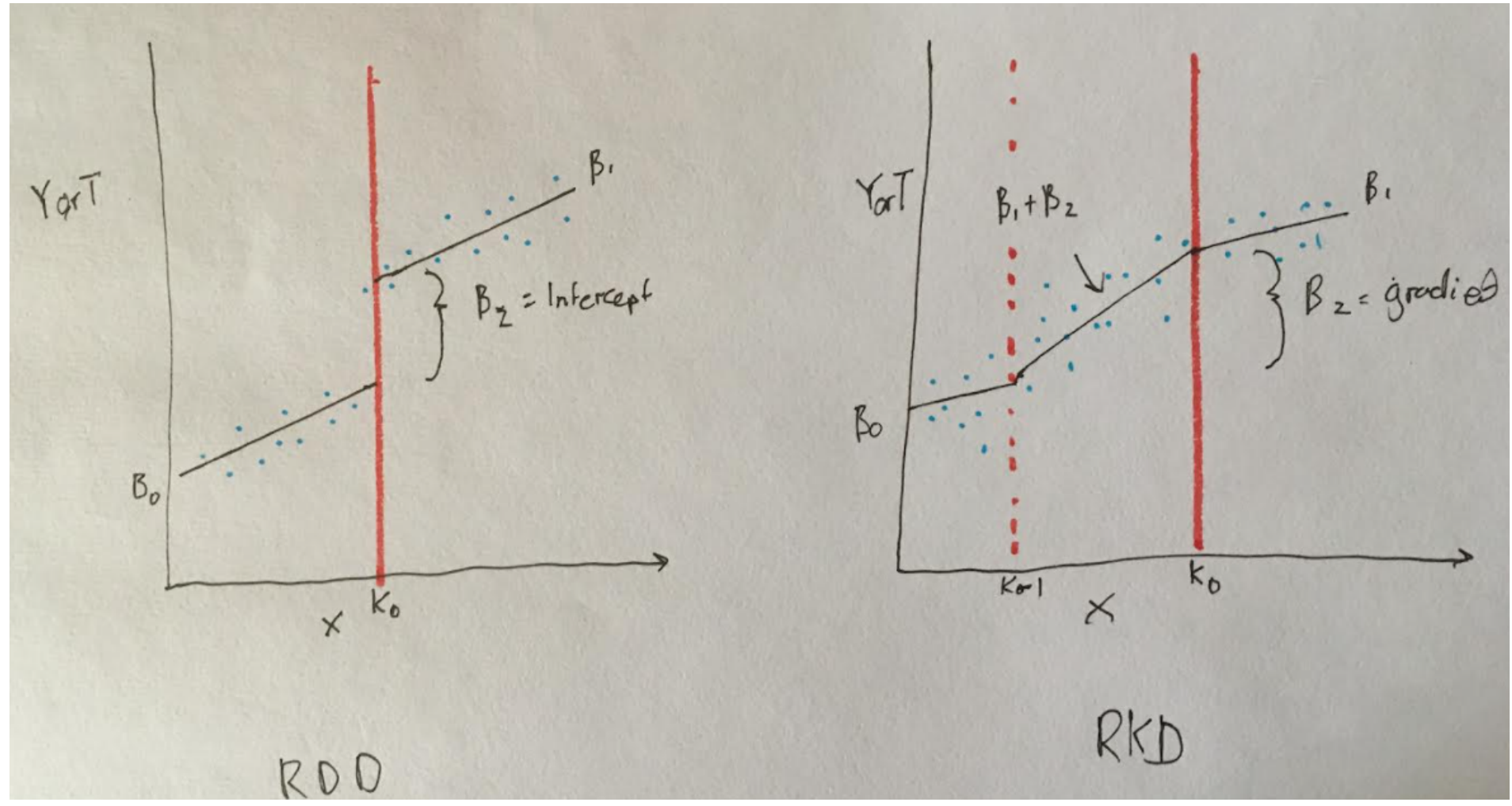

Note $\beta_{2}$ in both cases is the parameter of interest. $X$ is the variable that determines the treatment (e.g. age; also known as the running variable) whilst $Y / T$ is the outcome/ treatment (dosage) indicator (i.e hours of programme participation). 
By exploiting the age-related benefit rate, we can first estimate the effects of benefits rates on programme participation (in hours or completion stats). Then we can estimate the effects of benefit rates on programme related outcomes such as employment and further education. Since this is a migrant integration programme, we broadly refer to these outcomes as integration outcomes.

Assuming that the age-cut off has no effect on integration outcomes except via programme participation, we can calculate the direct effect of the Introduction Programme on integration outcomes.

The below directed acyclic graph (DAG) summaries the causal relationship between:

- $Z$ = age at the start of programme $Z$ (in months and years)

- $Z^{*}$ = special function of $Z$. Let age $K_{-1}$ is the lowest age at which programme participation changes due to expectations of benefit changes (e.g. 23, although this is unknown). If $Z \leq K_{-1}$ then $Z^{*}=0$. If $Z \geq 25$ then $Z^{*}=1$. Between ages $K_{-1}$ and $25, Z^{*}=\frac{Z-K_{-1}}{25-K_{-1}}$.

- $T=$ measure(s) of programme participation (e.g. hours completed). This is recorded a number of year $(3 / 4 / 5)$ after programme start.

- $X=$ confounders (observed and unobserved)

- $Y$ = outcome(s) $Y$ (e.g. education). This is recorded a number of year (3/4/5) after programme start.

- $B=$ Expected benefit rates for programme participation. Specifically, this is the expected period that a person will spend getting introduction benefit at full rate.

Directional arrows indicate causal effects, whilst bidirectional arrows indicate joint causation (e.g. usually due to additional confounders). DAGs are a useful alternative to a system of equations approach (see Pearl 2009). For instance, in the below $T$ is expressed as a function of $Z$ and $B$ (or $\left.Z^{*}\right)$. We do not assume any functional forms to start. 


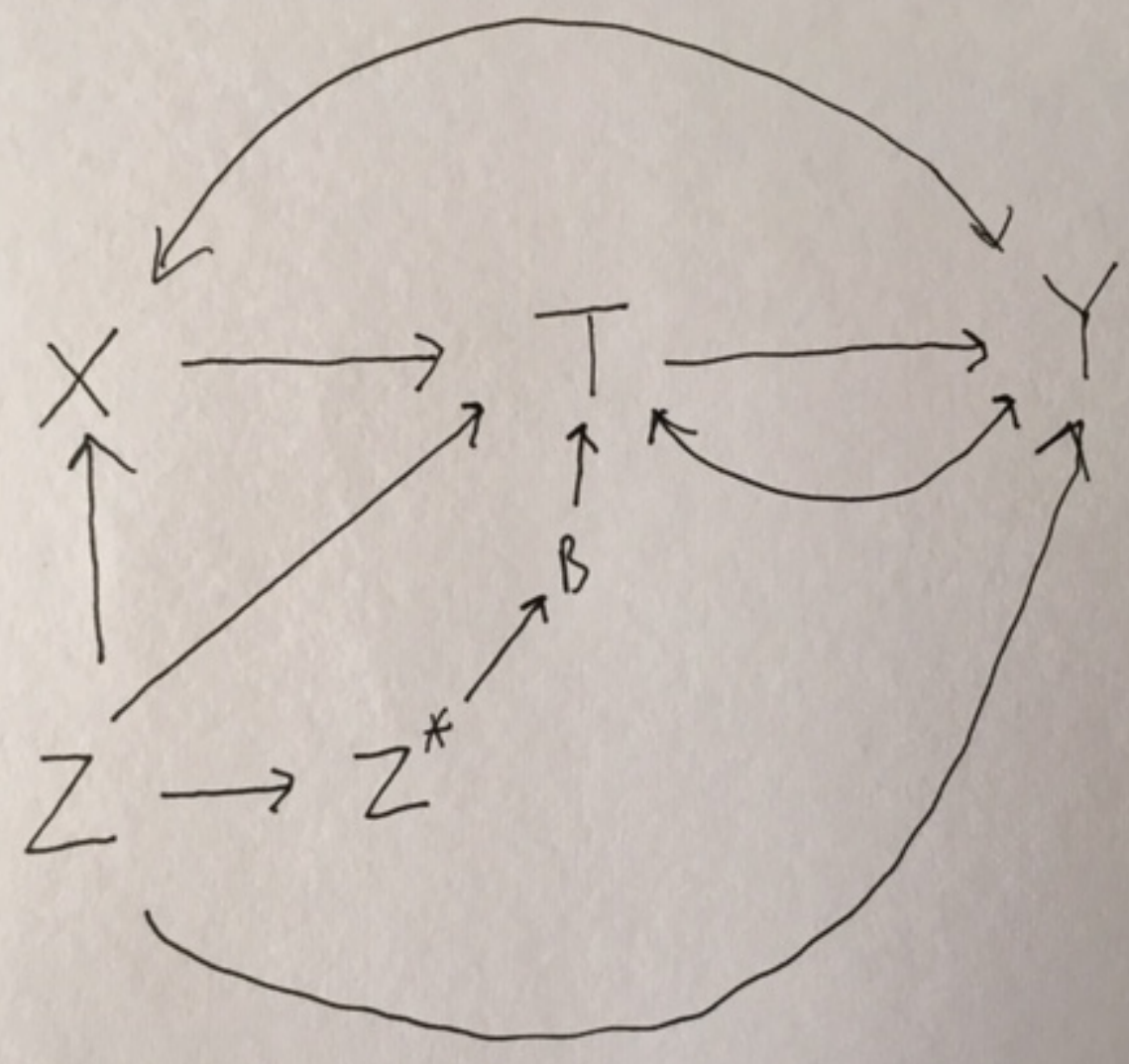

We assume that the relationship between age and participation differs between age $K_{-1}$ and 25 due to changes in expected benefit rates for participation $(B)$. We also assume that age $Z$ itself is exogenous. The above DAG indicates that we can estimate the effect of $Z^{*}$ on $T$ if we condition on $Z$ . However, a non-parametric estimator is not available because $Z$ perfectly determines $Z^{*}$. Therefore, we have to assume a parametric relationship between $Z, Z^{*}$ and $T$ (see next section).

\section{Statistical analysis}

We start by assuming that expected programme participation $(E(T))$ has a linear relationship with age. We only need the real relationship to be close enough to linear for estimation purposes (see robustness and sensitivity tests).

\section{Equation 1}

$$
E(T)=\beta_{0 T}+\beta_{1 T} Z+\beta_{2 T} Z^{*}
$$

The parameters $\beta_{2 T}$ indicates the effect of the age cut-off on $T$-- these are the causal parameters of interest. For example, $\beta_{2 T}$ is the causal effect of starting the programme at age 25 compared to age $K_{-1}$ (e.g. 23 in this example). A graphical example is below which shows the gradient of the regression lines: 


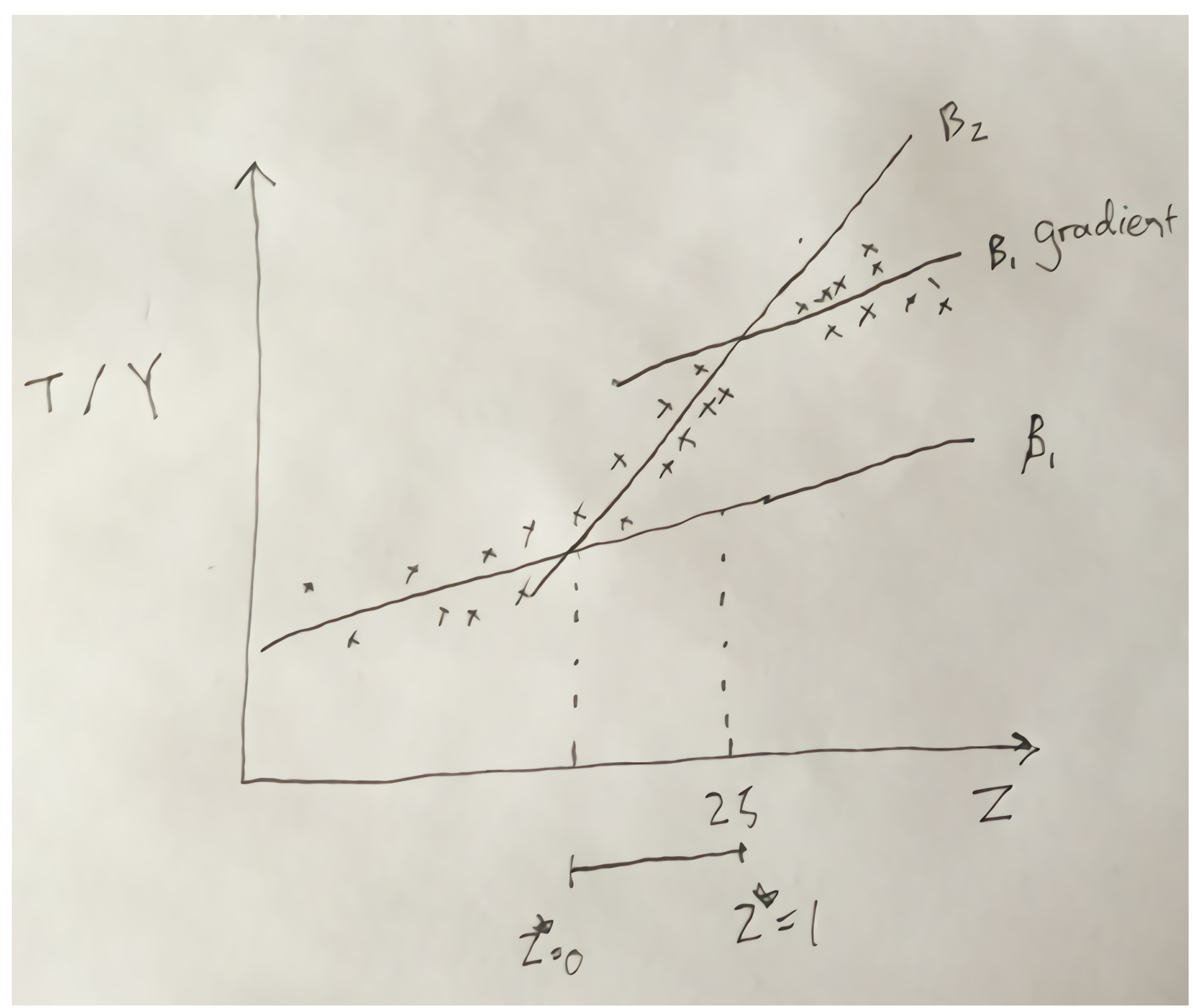

We purposefully restrict the sample's age range to prevent too much model extrapolation based on linear functional form (e.g. restricted to ages 20 - 30).

Using a similar equation, we can also identify the effects of the age cut-off on programme-related integration outcomes $Y$.

\section{Equation 2}

$$
E(Y)=\beta_{0 Y}+\beta_{1 Y} Z+\beta_{2 Y} Z^{*}
$$

Assuming that $Z^{*}$ has no effect on $Y$ except via $T$ then we can simply use the Wald Estimator (or equivalent) to estimate the effects of $T$ on $Y$ (i.e. $\delta$ ) in equation 3:

\section{Equation 3}

$$
\delta=\beta_{2 Y} / \beta_{2 T}
$$


Since the implementation of the Introduction Programme is up to municipalities, there can exist considerable heterogeneity in the treatment. Assuming $Z^{*}$ is exogenous to municipality of settlement, we can estimate the below with a random slopes model (or some variant thereof):

\section{Equation(s) 4}

$$
\begin{gathered}
E(Y)=\beta_{0 Y}+\beta_{1 Y} Z+\beta_{2 \text { Ymuni }} Z^{*} \\
\beta_{2 \text { Ymuni }}=\bar{\beta}_{2 Y}+e_{2 \text { muni }}
\end{gathered}
$$

Where essentially the parameter estimates of $\beta_{2 Y m u n i}$ can vary by municipality. The parameter of interest is the variance of $e_{2 m u n i}$. If the relative performance of programmes delivered by individual municipalities is of interest then we can estimate $e_{2 m u n i}$ using empirical Bayes estimators. The above assumes that participants are settled at random across municipalities; this is not the case for migrants in general. However, there is credible evidence that UNHCR refugees are initially dispersed at random across municipalities (see Bratsberg 2020). We will do a special analysis for this migrant group.

To test for subgroup effects, we can restrict our sample to particular groups of migrants nd re-run our estimators (see research questions section). Else we can achieve equivalent results using interaction terms.

Additional covariates may be used to test the sensitivity of the results to confounders. Most likely, these will include fixed effects for municipality, migrant group (e.g. refugee, family reunification) and/or country of origin.

Different types of migrant legally have different obligations under the Introduction Act. Further refugees are eligible for a special refugee grant if they are not receiving introduction benefits (see link).If the age profile of different types of migrants differ then our main estimators have to be stratified by migrant type to avoid confounding. This strategy is less efficient but probably has less chance of bias.

For looking at testing RQ6 (i.e. does the age 55 cut-off change participation); we will repeat the estimator in equation 1 replacing the age cut-off from 25 (23) to age 55 (53).

\section{Alternative estimator 1}

One alternative estimator assumes that for a restricted age range (say 23-25), age itself has no effect (or a neglible effect) on $T$ or $Y$ except through benefit rates. The estimating equations then become:

\section{Equation 1A}




$$
E(T)=\beta_{0 T}+\beta_{1 T} Z
$$

Where $\beta_{1 T}$ is now our causal parameter of interest. We can make similar changes to the other equations.

The upside of this approach is that within this age range, the age distribution of migrants is much more likely to be uncorrelated with other factors. For instance, the proportion of people aged 23-25 who are 25 is unlikely to be correlated with factors like year of arrival. This is only the case if the assumption of no (direct) age effect holds.

\section{Alternative estimator 2}

In the above, we expect that the relationship between age and participation is roughly the same for those aged between $20-23$ and 25 - 30. This is because those who start the programme in those age bands are not expected to change encounter age-related benefit changes.

However, we do not have to assume that this is the case. For each age group $g$ ( $g \in 1,2,3, g=1$ if aged between 20-23 etc), we can estimate separate regression models:

\section{Equation 1B}

$$
E(T)=\alpha_{g}+\beta_{g} Z
$$

Here, we can test for the existence of the effect of benefits by testing the null hypotheses:

$$
\begin{aligned}
& \beta_{g=0}=\beta_{g=2} \\
& \beta_{g=3}=\beta_{g=2}
\end{aligned}
$$

We can accomplish the above using interaction terms as well. The rest of the study has to be adjusted based on this new estimator. A graphical example of this approach is below: 


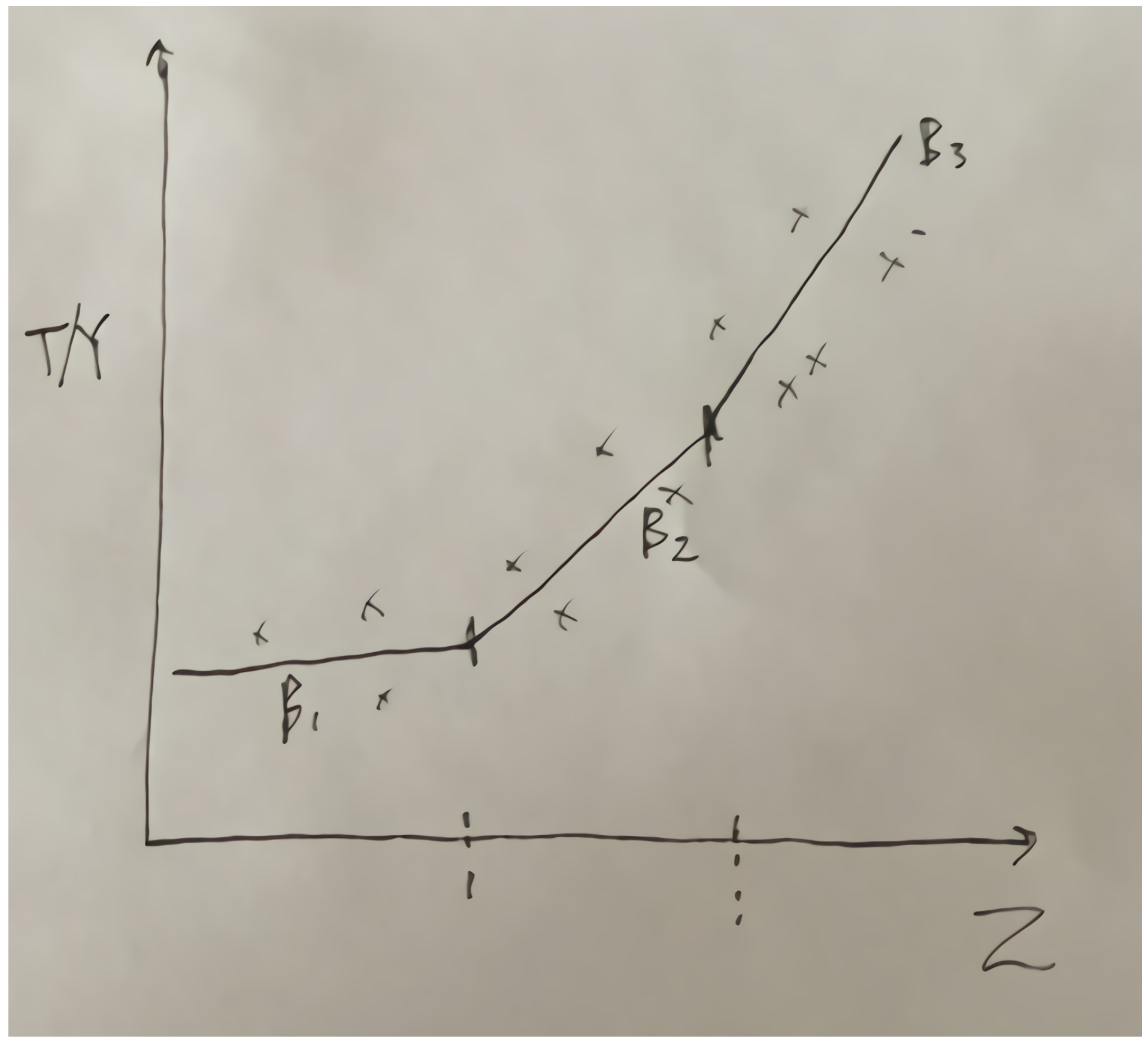

Note that if we find that:

$$
\beta_{g=1} \approx \beta_{g=3}
$$

Then this estimator is equivalent to our main estimator.

\section{Sensitivity and Robustness tests}

First, we need to test whether or not our age range variable $Z^{*}$ is correlated with observed and unobserved confounders. For observed confounders, we can model these using:

\section{Robust 1}




$$
E(X)=\beta_{0 X}+\beta_{1 X} Z+\beta_{2 X} Z^{*}
$$

Then we test the statistical significance of $\beta_{2 X}$ (or do an equivalent F-test). Confounders include characteristics (e.g. sex, employment status etc) at the start of the programme and 1/2 years before.

We can also use a placebo test to check if any other age period $\theta_{z}$ (e.g. 26 - 27) has an effect on participation. To do this, we must restrict the data to a range of ages either before 23 or after 26 before further analysis (e.g. ages 26 - 35). We can model this using:

\section{Robust 2}

$$
E(T)=\beta_{0 T}+\beta_{1 T} Z+\beta_{2 T} \theta_{z}
$$

We then test the significance of $\beta_{2 T}$. It is possible that age groups before 22 may have sharp changes in the relationship between age and participation due to several changes between age and other aspects of Norwegian society during this particular stage of life (e.g. minimum wage).

Another placebo test is to check for a relationship between $Z^{*}$ and outcomes that cannot be plausibly affected by the introduction programme. However, since the integration programme potentially affects many outcomes, it is not entirely clear at this stage what these other outcomes can be.

The extra rise in benefits after age 25 is publically known. Whilst attendance in the Introduction Programme is mandatory for some migrants, individuals could strategically defer their start date in anticipation of higher benefits. This is important because a key assumption of both RKD and RDD is that the distribution of the running variable (i.e. age at the start) is smooth. For example, the number of participants who start the programme at 25 should not be unexpected high or low. We can test this assumption by looking at a histogram of age and conducting a McCrary test (2007). We may have to adapt this test to accommodate our particular research design (e.g. kink point starts at $K_{-1}$ ).

Example test from McCrary (2008) 

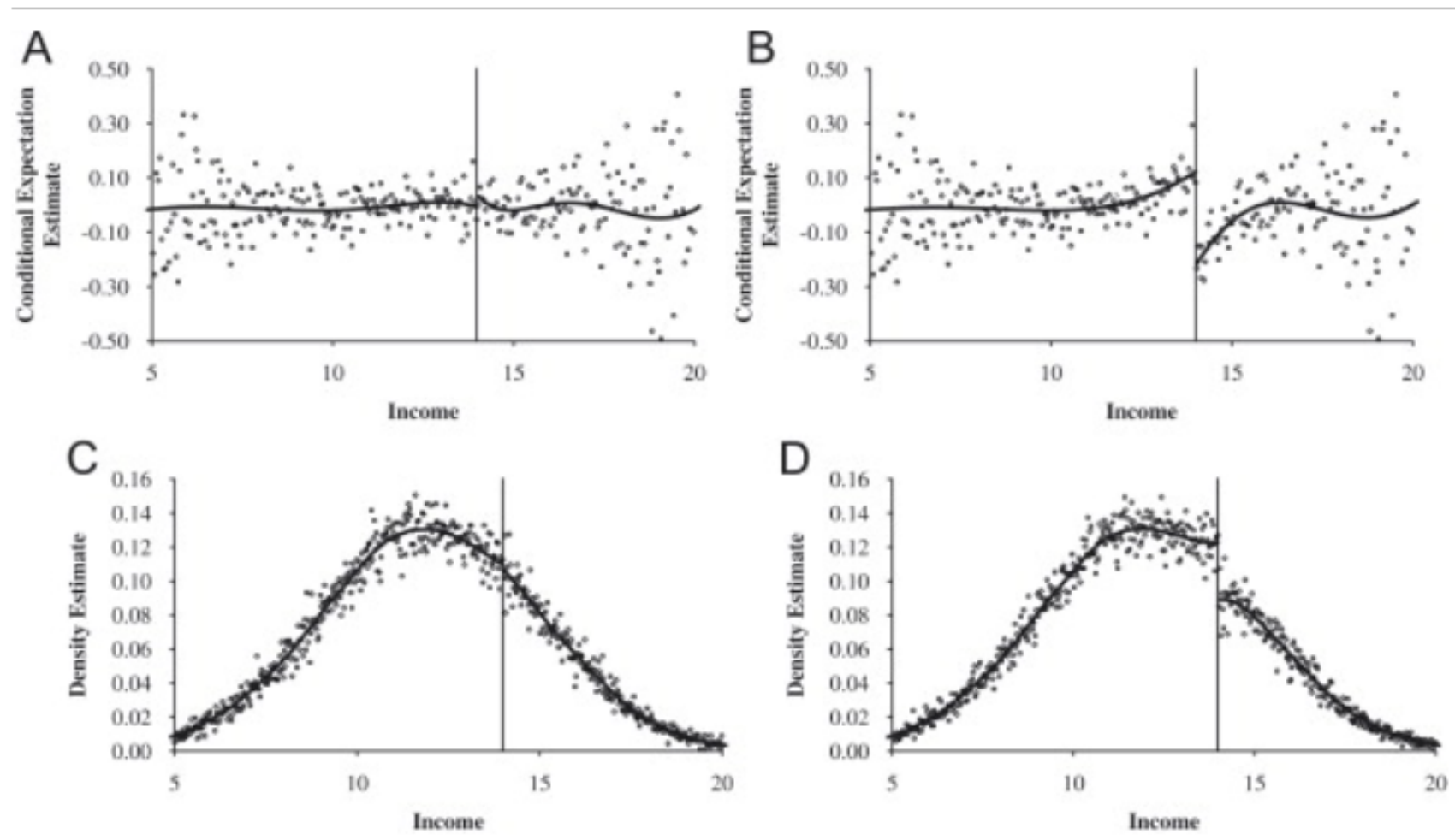

Download : Download full-size image

Fig. 2. Hypothetical example: gaming the system with an income-tested job training program: (A) conditional expectation of returns to treatment with no pre-announcement and no manipulation; (B) conditional expectation of returns to treatment with pre-announcement and manipulation; (C) density of income with no pre-announcement and no manipulation; (D) density of income with pre-announcement and manipulation.

Throughout this document, it's our conjecture that (expected) benefit changes start to affect programme participation at $23\left(K_{-1}=23\right)$ and the effects increases linearly over time. We do not know whether this is true; the participation effects may only be evident at later ages (i.e. 24). We will try different values of $K_{-1}$ between 23 and 25 to see if this affects results. Note that if $K_{-1}=25$ then the design is equivalent to regression discontinuity. We may adopt a model fit method proposed by Landais (2015) to locate unknown kink point $K_{-1}$. We will also test the sensitivity of the estimate to different functional forms (i.e. polynomials, see below).

Another sensitivity test is to shrink the age band of our sample from 20 - 30 to some other value (e.g. 21 - 28). This tests the sensitivity of our results to our functional form. We can also add polynomials for $Z$ and $Z^{*}$ to accommodate non-linearity. The choice of age band is important as RKD needs a relatively wider bandwidth (i.e. age range) than RDD. Furthermore, we may adopt other methods for finding the 'optimal' age band (see comments to Lundqvist et al 14). 
Finally, some assumptions cannot be tested using statistics. An obvious example is the absence of unobserved confounders. Another is the existence of alternative explanations / mediating effects that could explain changes in programme participation between ages $K_{-1}$ and 25 . We will continue to conduct shoe-leather research (such as reviewing policy documents and interviewing policymakers) to uncover further information that can challenge our assumptions.

\section{Relation to research questions}

Here's the list of research questions and the analysis that can be done for each of them:

1. What is the effect of the age-cut off (via benefit rate) on programme participation? [Equation 1]

2. What is the effect of the age-cut off (via benefit rate) on integration outcomes? [Equation 2]

3. What is the direct effect of programme participation on integration outcomes? [Equation 3]

4. What is the level of variance in the efficacy of the participation programme? [Equation 4]

5. Do heterogeneous effects exists for a) programme participation and b) integration outcome? [Subgrouping and re-estimating models]

For RQ5, we will look at subgroups effects by:

- Sex

- Presence of children. Parents may be more or less sensitive to the economic incentives of the introduction benefit. Parents of dependents may also be eligible for other benefits.

- Migrant type (Refugee/ Family reunification/ Other(?)). Different migrant groups have different rights and obligations. These groups also differ in several characteristics and refugees are eligible for alternative grants. Migrant type is a potential confounder if the age profiles differ across migrant groups.

- UN High Commissioner for Refugees (UNHCR) refugees only: UNCHR refugees are initially dispersed at random across Norway (see Bratsberg et al 2020). The initial region of dispersal has a strong impact on the region of settlement (i.e. region where the introduction programme took place). The random nature of dispersal for this subgroup allows us to address bias caused by self selection in the region of settlement.

- Country of Birth: The demography of migrants change over time to reflect Norwegian immigration policy and international developments (e.g. mass migration events due to civil war). Treatment effects by country of birth allow us to forecast the efficacy of the Introduction Programme for future migrant cohorts. In addition, we can spot areas of improvement.

6. What are the effects of the changes in rights and obligations at age 55 on programme participation? [Equation 1]

Additional research questions can be added post-hoc but they must be treated as more exploratory. 
For participants aged roughly between $K_{-1}$ and 25 at the start of the programme;

- H1. participants starting closer to age 25 have greater completion rates, hours spent, and introduction benefits earned. This is expected due to an increase in benefit rates.

- H2. participants starting closer to age 25 have greater labour market participation and further training. This is expected due to increases in programme participation.

- H3. We expect some variance in efficacy across municipalities since the exact contents of the programme are left at the discretion of municipalities (as is the benefits).

We also believe heterogenous programme effects exists by:

- Sex

- Presence of children

- Migrant type (Refugee/ Family reunification)

- Country of Birth

For RQ6:

- H4. participation in the introduction programme will substantially decrease after age 55 (or slightly beforehand). This is expected due to changes in obligations after age 55.

\section{Previous studies}

The introduction programme has been explored in various non-peer reviewed evaluation papers. Furthermore, it features several cross-national comparisons of Nordic integration policies. We will continue to read papers related to the introduction programme (including other papers cited).

The most relevant recent paper on the integration programme comes from a Nordic Council funded project looking at the cross-national comparisons of integration programmes (Hernes et al 2019; and resulting publications). An evaluation by Tronstad (2015) looks at the details of the programme in more detail. A check of their background section shows no previous studies have used the design proposed in this document. Amongst other papers reviewed (see end), I also find no evidence of another quasiexperimental evaluation of the Introduction Programme.

The first evaluation of the programme (Kavli et al 2007) uses a control group of migrants who settled in Norway before the introduction of the programme. This is probably the closest quasi-experimental estimator of the programme effects. 


\section{Data collection}

\section{Data sources/ Datasets used}

Norway has a National Register (Folkeregister) which forms the basis for the tax register, the electoral register and population statistics. The national registry ensures that all citizens receive information from public authorities and that their rights and obligations are safeguarded. The National Register includes information on all people who are or have been residents in Norway.

Information on participants of the Introduction Programme is available from Statistics Norway.

We plan to use data from Statistics Norway on the Introduction Programme and link it to National Register data.

We are primarily interested in participants who first enrolled on the Introduction Programme on or before 2016.

\section{Data restrictions}

Data is available via protected access to Norwegian researchers. Applications outside Norway are subject to special access requirements (see https://www.ssb.no/en/omssb/tjenester-og-verktoy/data-tilforskning\#Microdata_applications_from_outside_Norway)

\section{Data identifiers}

Introduction Programme: https://www.ssb.no/en/omssb/tjenester-og-verktoy/data-tilforskning/introduksjonsordningen

\section{Variable/Codebook}

The variable list for the introduction programme is downloadable here (in Norwegian):

https://www.ssb.no/en/omssb/tjenester-og-verktoy/data-til-forskning/introduksjonsordningen

A full translated variable list is at the end of this document.

Stats Norway published stats on employment outcomes from the participants and benefits data so it is linkable. Furthermore, since not every eligible participant may enrol, we may also find data on all eligible participants (e.g. refugees and reunion members) (Hernes et al 2019). 


\section{Sample}

For our estimation, we would require a sample of all eligible participants in the programme (determined by migrant type, i.e. refugees and their spouses, as in Hernes et al 2019) aged 18 - 55 . We'd restrict the sample to a much smaller age range (20-30) for actual models however the full age range will allow us to contextualise our findings (i.e. what proportion of migrants are 23-25).

At worst, we can base our numbers on Hernes et al (2019) who had a sample of participants of the introduction programme.

\subsection{Norway}

Table 2: Individual characteristics of refugees and family migrants to refugees in Norway, by year of settlement

\begin{tabular}{|c|c|c|c|c|c|c|}
\hline & $2008-2009$ & 2010-2011 & $2012-2013$ & $2014-2015$ & 2016 & Total \\
\hline Women & 48.5 & 45.6 & 48.2 & $3^{8.7}$ & 31.9 & 41.9 \\
\hline Age (years) & 30.0 & 28.8 & 29.1 & 29.1 & 29.0 & 29.2 \\
\hline \multicolumn{7}{|l|}{ Age-group } \\
\hline $20-25$ & 25.2 & 29.1 & 30.5 & 32.8 & 33.2 & 30.6 \\
\hline $26-35$ & 46.8 & 46.2 & 46.1 & 44.5 & 43.6 & $45 \cdot 3$ \\
\hline $3^{6-45}$ & 21.5 & 18.7 & 18.9 & 17.1 & 18.1 & 18.6 \\
\hline $46-55$ & 6.4 & 5.9 & 4.6 & 5.7 & 5.1 & 5.5 \\
\hline Married & 43.2 & 39.1 & 42.4 & 43.4 & 47.0 & 43.1 \\
\hline Has children $<=6$ years old & 41.7 & 27.6 & 29.0 & 23.5 & 22.2 & 27.4 \\
\hline \multicolumn{7}{|l|}{ Country of birth } \\
\hline Afqhanistan & 9.7 & 12.6 & 7.6 & 4.9 & 3.1 & 7.2 \\
\hline Eritrea & 17.2 & 27.0 & 23.1 & 29.3 & 30.4 & 26.0 \\
\hline Iraq & 14.3 & 7.0 & 3.1 & 1.3 & 1.3 & 4.7 \\
\hline Iran & 2.9 & $5 \cdot 3$ & 5.7 & 2.9 & 1.5 & 3.6 \\
\hline Somalia & 14.1 & 21.0 & 30.5 & 18.7 & 4.8 & 17.7 \\
\hline Syria & 0.8 & 0.5 & 4.8 & 24.7 & 43.8 & 16.8 \\
\hline Other & 41.1 & 26.7 & 25.3 & 18.1 & 15.0 & 24.0 \\
\hline \multicolumn{7}{|l|}{ Education } \\
\hline Primary education & 50.8 & 47.6 & 48.3 & 39.2 & 33.4 & 43.1 \\
\hline Secondary education & 6.9 & 11.7 & 8.2 & 3 & 2.4 & 6 \\
\hline Tertiary education & 18.9 & 15.4 & 13.7 & 11.9 & 11.8 & 14 \\
\hline Missing values & 23.4 & 25.4 & 29.9 & 45.9 & 52.3 & 37 \\
\hline \multicolumn{7}{|l|}{ Centrality } \\
\hline Metropolitan area & 14.5 & 12.2 & 11.4 & 7.7 & 8.7 & 10.5 \\
\hline Other large cities & 21.2 & $17 \cdot 3$ & 15.2 & 13.3 & 16.5 & 16.3 \\
\hline Cities & 24.6 & 24 & 21.8 & 20.6 & 21 & 22.1 \\
\hline Towns & 24 & 24.2 & 27.4 & 28.7 & 25.1 & 26.2 \\
\hline Rural/remote municipalities & $15 \cdot 7$ & 22.3 & 24.2 & 29.7 & 28.6 & 24.9 \\
\hline \multicolumn{7}{|c|}{ Reason for being granted a residence permit } \\
\hline Family reunification & 19.2 & 13.5 & 13.2 & 12.5 & 12.6 & 13.9 \\
\hline Convention refugee & $64 \cdot 3$ & 71.7 & 71.0 & 74.5 & 75.4 & 71.9 \\
\hline Subsidiary protection & 1.1 & 0.8 & 1.7 & 0.8 & 0.5 & 1.0 \\
\hline UN Quota status & $15 \cdot 3$ & 14.0 & 14.1 & 12.2 & 11.5 & 13.2 \\
\hline Other & 0 & 0 & 0 & 0 & 0 & o \\
\hline Participants (N) & 7,543 & 8,655 & 9,014 & 12,691 & 9,889 & 47,792 \\
\hline
\end{tabular}


Note: For context there are >20,000 participants in 2019 link

Based on this table, we estimate roughly 25449 individuals aged between 20-30 from 2008 - 2016:

$>\quad((0.306+0.453 / 2) * 47792) \%>\% \operatorname{round}(\theta)$

[1] 25449

Since we do not know the exact distribution of all our variables, we must use simulations to determine the statistical power of our analysis. For each simulation, we create a dataset with 25449 cases and these variables of interest:

- $Z$ (age) is drawn from a uniform distribution with min and max of 20 and 30

- $Z^{*}$ is 0 if $Z<23$ and 1 if $Z \geq 25$. If $Z$ is between 23 and 25 it is $(Z-23) / 2$.

- $Y_{1}$ is a random variable that is normally distributed $\sim N(0,1)$

- $Y_{2}$ is a binary variable that takes the value of 0 and 1 with equal probabilities

Here $Y_{1}$ and $Y_{2}$ represent participation/ outcomes variables mentioned in the statistical analysis. We simulate the data 10,000 times and for each simulation we estimate the linear models:

$$
\begin{aligned}
& E\left(Y_{1}\right)=\beta_{0 Y_{1}}+\beta_{1 Y_{1}} Z+\beta_{2 Y_{1}} Z^{*} \\
& E\left(Y_{2}\right)=\beta_{0 Y_{2}}+\beta_{1 Y_{2}} Z+\beta_{2 Y_{2}} Z^{*}
\end{aligned}
$$

We are interested in the distribution of $\beta_{2 Y_{1}} Z^{*}$ and $\beta_{2 Y_{2}} Z^{*}$ which will give us the effect sizes needed to achieve statistical significance at the usual $p>0.05$ threshold.

Under the null hypothesis:

$$
\beta_{2 Y_{1}} Z^{*}=\beta_{2 Y_{2}} Z^{*}=0
$$

Only $5 \%$ of cases have a value of:

- $\left|\beta_{2 Y_{1}} Z^{*}\right|$ larger than 0.062

- $\left|\beta_{2 Y_{2}} Z^{*}\right|$ larger than 0.031

Here the effect size is due to an increase in introduction benefit rates from $2 / 3$ to full over 2 years. We can in theory detect any effect size that is greater than $6.2 \%$ of standard deviation for continuous variables or $3.1 \%$ for binary variables. For context, Tronstad (2015) shows that the difference in the proportion of those in work or education in the $18-25$ and $26-32$ year groups is roughly $6 \%$ (see table 4.1).

This is all based on limited years of data and the actual sample size will probably be higher leading to greater statistical power. Therefore, we ought to be able to detect relative modest effect sizes. 


\section{Variables}

The variables used are all derived from Norwegian register data which is complex and require some manipulation. Key raw variable names (translated) from the Norwegian register are included in the appendix.

$Z$

- age $=$ age at the start of introduction programme (derived from programme start and date of birth)

$T$ [Collected $3 / 4 / 5$ years (variable) after start date]

note for non-participants most programme variables (e.g duration) are recoded to zero

- progDuration $=$ time spent in the programme (derived from start and end dates)

- progBenefitNOK = sum of intro. benefit collected up to date (based on total during reporting years)

- progBenefitMonths $=$ sum of months receiving intro. benefits up to that date. Note we are unsure if exact hours are recorded.

- progBenefitRate $=$ progBenefitNOK $/$ progBenefitMonths (checking that a discontinuity occurs after participant reach 25)

- progStatus $=$ Status of participation after $3 / 4 / 5$ year in the programme. Potentially a outcome of interest signifying leave and delays to completing hte programme (see limitations)

- progCourses_[X] = dummy variable indicating whether the participant has done a variety of courses / vocational training (e.g. subjects in primary school)

- progTestScores_[ $[\mathrm{X}]=$ Language and social/ cultural understanding test scores as measured by the programme. Note We are in the process of negotating access to this data which we believe is kept in a separate database from the Introduction benefits data. We are unsure of the structure of this database. Since we only observe test scores for participants, this leads to selection bias issues (see limitations).

$Y$ [Collected $3 / 4 / 5$ years after programme start]

- outEducation = in education $/$ training

- outEmployment = in employment

- outWage = sum of earnings in reporting year

- outBenefit_[X] = total benefits of type $[X]$ (e.g. unemployment) collected in reporting year $3 / 4 / 5$ years after programme start

$X$ [Recorded at programme start and 1/2 year beforehand]

- Sex 
- Martial status

- Type of migrant: Determine programme eligibility and duties/ obligations. Refugees are also eligible for a loan as an alternative to the introduction programme. Different migrant types may have different ages which may cause confounding.

- country of birth

- cohort (date of entry into Norway)

- placeboBenefit_[X] = Whether participant was receiving other unrelated benefits (e.g. health). The exact benefits need to be investigated due to the way that the introduction programme may affect other benefits.

- tenureStatus $=$ Whether participants cohabit with parents (see limitations and other considerations)

[Unknown other variables for robustness tests. Note prev. education info for migrants is known to be poor]

- nChildren = number of children in participant's family. This can be an important subgroup effect.

\section{Other}

- municipality of settlement at the start of programme

- municipality at end of programme

- receipt of other benefits

Other potential secondary outcomes and variables for robustness tests can be gained from the Norwegian register.

\section{Limitations and other considerations}

Not all under 25s face the same financial challenges; single parents, in particular, may struggle and this was noted by the Norwegian Government when the Introduction Act was introduced (2002). To address the national Government relies upon other benefits (i.e. living expenses benefits) and the discretion of individual municipalities to address differing needs. Municipalities have the discretion to pay some under 25s the higher rate of benefits (see Kavli et al 2007, p.51). Kavli et al report that the majority (64\%) of municipalities do however pay only $2 / 3$ benefits to under $25 \mathrm{~s} ; 15 \%$ always pay full benefits to under 25 s whilst $13 \%$ did so occasionally. This rule exception could decrease the power of our statistical estimates. This is particularly true for RQ4 which looks at heterogeneous programme effects across municipalities.

Strictly speaking, we can only identify causal effects for a narrow age band. We cannot know if the findings can be extrapolated over other ages group but this is a weakness of every non-experimental 
study. Under 30s make up the majority of migrants on the introduction programme so our findings are likely to still be policy-relevant (Hernes et al 2019).

In 2016, Norway changed the family reunification law. After this date, only refugees and spouses over 24 are eligible for family reunification. This cut-off means that there will be a higher proportion of family reunification migrants at age 25 compared to 24 (and below). This changes the causal model that we assume in this document. Additional adjustments must be made to accommodate data after 2016 (if possible).

Other age-based discontinuities at $K_{-1}$ and 25 may affect the causal design. Norway has no minimum wage laws although sector wages are influenced by trade unions. A brief search of trade union sectorial minimum wages yields no minimum wage changes between 23-26. Another brief search of the benefits system in Norway indicates no changes in eligibility or amount received between 23-26 except for disability benefits which are different for those under 26 . Research into other age-based factors in the age range 20-25 will continue as part of the project. A masterlist of benefits is the database of benefits data collected by Stats Norway (https://www.ssb.no/en/omssb/tjenester-ogverktoy/data-til-forskning/fd-trygd).

Another consideration is that migrants in the introduction programme, much like their native Norwegian counterparts, are eligible to economic leave under certain circumstance such as childbirth and taking care of children (see here, and p.677-678 Hagelund 2005). Whether the introduction benefit reduces delays in programme completion can be a policy-relevant question.

Related to age-based discontinuity, age may not have a linear relationship to programme participation or outcomes in the ages between 20 to $K_{-1}$. This is due to several changes between age and other aspects of Norwegian society during young adulthood (e.g. minimum wage). We may therefore have to limit our sample to those aged 22 or over which will change our modelling strategy.

We have spoken to a NAV official as part of the research and will continue to communicate with NAV to investigate the deployment of the Introduction Programme. From initial conversations, we know that:

- participants are well aware of the under 25 benefits rule

- for that municipality, benefits are paid out monthly

- participants can have part-time jobs during but it's not common

We only observe programme test scores for programme participants; this will induce selection bias. We will consider if possible identification strategies including: heckit seleciton models, IV and bounds analysis (i.e. partial identification). There is the possbility that in this case no credible estimator exists.

Finally, there is the possibility of translation errors that might affect our research design: the lead author cannot speak Norwegian and used google translate to translate key pieces of background literature. 


\section{References and other relevant literature}

\section{Methods and RKD}

Card, D. et al. (2017) 'Regression Kink Design: Theory and Practice', in Cattaneo, M. D. and Escanciano, J. C. (eds) Advances in Econometrics. Emerald Publishing Limited, pp. 341-382. doi: 10.1108/S0731-905320170000038016.

Landais, C. (2015) 'Assessing the Welfare Effects of Unemployment Benefits Using the Regression Kink Design', American Economic Journal: Economic Policy, 7(4), pp. 243-278. doi: 10.1257/pol.20130248.

Lundqvist, H., Dahlberg, M. and Mörk, E. (2014) 'Stimulating Local Public Employment: Do General Grants Work?', American Economic Journal: Economic Policy, 6(1), pp. 167-192. doi:10.1257/pol.6.1.167.

McKenzie, D. (2016) Tools of the Trade: The Regression Kink Design. World bank blogs. Available at: https://blogs.worldbank.org/impactevaluations/tools-trade-regression-kink-design (Accessed: 16 September 2016).

McCrary, J. (2008) 'Manipulation of the running variable in the regression discontinuity design: A density test', Journal of Econometrics, 142(2), pp. 698-714. doi: 10.1016/j.jeconom.2007.05.005.

Pearl, J. (2009) Causality: Models, reasoning and inference. 2nd edn. Cambridge, UK: Cambridge University Press.

\section{Introduction programme}

Bratsberg, B., Raaum, O. and Røed, K. (2017) 'Immigrant Labor Market Integration Across Admission Classes', p. 37.

Bratsberg, B. et al. (2020) 'How Settlement Locations and Local Networks Influence Immigrant Political Integration', American Journal of Political Science, p. ajps.12532. doi:10.1111/ajps.12532.

Introduction act 2003 (english trans.) https://lovdata.no/dokument/NLO/lov/2003-07-04-80

Kavli, H., Hagelund, A., and Bråthen, M (2007) 'Med rett til å lære og plikt til å delta : en evaluering av introduksjonsordningen for nyankomne flyktninger og innvandrere (trans: With the right to learn and the duty to participate: an evaluation of the introduction scheme for newly arrived refugees and immigrants)', FAFO report, p. 244. 
Hagelund, Anniken. 'Why It Is Bad to Be Kind. Educating Refugees to Life in the Welfare State: A Case Study from Norway'. Social Policy and Administration 39, no. 6 (December 2005): 669-83. https://doi.org/10.1111/j.1467-9515.2005.00463.x.

Hernes, V. and Tronstad, K.R. (2014) Komparativ analyse av introduksjonsprogram i Norge, Sverige og Danmark (trans: Comparative analysis of introductory program in Norway, Sweden and Denmark). Available at: https://www.imdi.no/contentassets/f660656dbb3444f8b02189009c6948a5/rapport-2014.komparativ-analyse-av-introduksjonsprogram-i-norge-sverige-og-danmark (Accessed: 16 September 2021).

Hernes, Vilde, Jacob Nielsen Arendt, Pernilla Andersson Joona, and Kristian Rose Tronstad. 2019. Nordic Integration and Settlement Policies for Refugees. 2019:529. TemaNord. Copenhagen: Nordic Council of Ministers. https://doi.org/10.6027/TN2019-529.

Hernes, V. et al. (2020) 'Rapid or long-term employment? A Scandinavian comparative study of refugee integration policies and', Journal of European Public Policy, p. 22.

Norwegian Government. 'Om Lov Om Introduksjonsordning for Nyankomne Innvandrere (Introduksjonsloven). Ot.Prp. Nr. 28 (2002-2003) (Trans. About the Law on the Introduction Programme for Newly Arrived Immigrants)', 2002. https://www.regjeringen.no/no/dokumenter/otprp-nr28-2002-2003-/id171771/.

Proba (2019) Evaluering av tilskudd til kommunenes bosettings- og integreringsarbeid (trans: Evaluation of grants to the municipalities settlement and integration work). Available at: https://proba.no/wp-content/uploads/rapport-2019-01-evaluering-av-integreringstilskudd.pdf (Accessed: 16 September 2021).

Tronstad, K (2015) Introduksjonsprogram for flyktninger i norske kommuner Hva betyr organiseringen for overgangen til arbeid og utdanning? (trans: Introduction program for refugees in Norwegian municipalities. What does the organization mean for the transition to work and education?). NIBR report. Available at: https://evalueringsportalen.no/evaluering/introduksjonsprogram-for-flyktninger-inorske-kommuner.-hva-betyr-organiseringen-for-overgangen-til-arbeid-og-utdanning (Accessed: 16 September 2021).

\section{Supplement}

\section{Stat Norway introduction programme variable list}

Full variables list (google translated) link: 
Serial number person

County - offers program

Municipality - offers program

District - offers program

Task year

Sex

Marital status at last contact

Age - made in Statistics Norway

Does the recipient have income-generating work in addition to the introduction benefit at the last contact?

What courses and vocational preparation measures has the recipient participated in during the reporting year? Norwegian language training

Language practice

Approval of education

Work: Collected in one variable from and including 2011, with valid values in ARB_OFF from and including 2012

Work in public: From 2012 onwards, valid values are the same as for "WORK" (both public and private)

Work privately

Work practice

Subjects in primary school

Primary school

Vocational testing

Courses under the auspices of the municipality / state

Subjects in high school

other

Status of the recipient's participation in the introduction scheme at the end of the reporting year? Start date for participation in the introductory scheme (ddmmåå)

End date for participation in the introductory scheme / went on leave from date (ddmmåå)

Which months during the year has the recipient received an introductory benefit?

Total introductory benefit during the reporting year

Number of months of benefit

Number of municipalities with support 